\title{
Understanding the Professional Project Manager: Cosmopolitans, Locals and Identity Work
}

\author{
Damian E Hodgson \\ Manchester Business School, University of Manchester, Booth Street West, Manchester M15 6PB

\section{Damian.hodgson@manchester.ac.uk}

Steve Paton

Strathclyde Business School, University of Strathclyde, 199 Cathedral St, Glasgow G4 0QU

\section{Steve.paton@strath.ac.uk}

\begin{abstract}
An abiding concern and mission in the work of Peter Morris over many years has been to develop project management as a profession, with particular concern to bridge the rift between abstract theory and practice (cf. Morris 2006; 2011; 2013). That this is necessary reflects project management's status as a new 'expert occupation' (Reed, 1996), built primarily upon a specific set of competencies seen as applicable to a range of activities across industries. As the field has grown, project management practice has been increasingly standardised as practitioners have been 'credentialised' with a standard set of competencies, while being employed in an increasingly diverse variety of workplaces. As a result, many project managers rely upon both local 'familiarity' and domain knowledge of company and industry, and at the same time a formal global 'competence' in the practice of project management.

In this paper, we seek to explore this duality, examining how project managers rely in part on the authority and expertise of the profession and in part rely instead upon technical expertise and industry/organisational experience to perform their role, and how these two are reconciled. Drawing on thirty nine semi-structured interviews in an industry where project management is established and 'mature', we adopt Gouldner's (1958) cosmopolitan and local typologies to understand how project managers orientate themselves in relation to the two main institutions that dominate their employment. It further indicates that this binary distinction is complicated by a number of contradictions which project managers must make sense of in construction of a valid identity. Some project managers draw heavily on the cosmopolitan discourse, others draw on the localist discourse, but the majority seek to articulate positions which integrate both. In constructing the intermediate
\end{abstract}


orientations project managers are implicitly challenging the utility of the concept of portable bodies of knowledge and universal methodologies. This questions the strategy of professionalism for this occupation and indeed opens a wider debate about the efficacy of new corporate professionalism.

Further this research implies that both professional bodies and employers need to understand how to navigate these discourses. This reveals dual challenges. For the professions the challenge is to convince locals to become cosmopolitans by adopting the trappings of professionalism but without contesting too far the sovereignty of the corporation as employer. For corporations, the challenge is to capture the broad expertise of the cosmopolitan without compromising their affiliation to their employer. Ironically both institutions are complicit, often working together to meet different ends.

Finally this research suggests that project management is rich in identity work and that this may provide an important lens to analyse the ongoing evolution of the wider management professions, specifically in relation to the compromises that professionalism brings to this particular form of expert labour. 


\section{Understanding the Professional Project Manager: Cosmopolitans, Locals and Identity Work}

\section{Introduction}

The knowledge economy has been characterised by the proliferation of new 'expert occupations' (Reed, 1996; Muzio et al, 2007). Project management is one such occupation whose approach to professionalisation in the UK has been described as matching the template of the 'corporate profession'. Corporate professions (Muzio et al, 2011; Paton et al, 2013) comprise a mix of characteristics inherited from the traditional professions (Burrage and Torstendahl, 1990; Johnson, 1972) such as knowledge-based enclosure (Crawford et al, 2006; Morris, 1997), alongside contemporary characteristics such as closer relationships with employers and purchasers of expert labour (Paton et al, 2013).

This professionalisation of project management (Hodgson, 2008) has resulted in an occupation which sees individuals 'credentialised' against an increasingly standardised body of knowledge. While this body of knowledge has been a key part of the professionalisation journey so far, its impact has been questioned by Peter Morris $(2006,2013,2014)$. In a series of papers, he argues, that the project management body of knowledge is becoming less applicable to the more pluralistic context within which Project Management is being applied. Moreover, he argues, its composition, which emphasises formal knowledge (episteme) over skill (techne) and wisdom (phronesis), is not fit for purpose as the 'needs of the discipline are fundamentally biased towards application, and towards the discipline as a broadly based, pluralistic, interdisciplinary approach to managing change' $(2013, p 5)$. This fundamental issue of knowledge 'fit' creates tensions as project managers attempt to discharge the responsibilities of their role within the employing context while working in a way that befits their professional status.

Drawing on an extensive empirical study of project managers working within multi-national, project oriented companies in the UK defence industry, and referencing Gouldner's $(1957,1958)$ 'local' and 'cosmopolitan' ideal types, the objective of this paper is to explore, through an analysis of alternative discourses, how project managers construct identities which allow them to reconcile inherent tensions between their professional status as a project manager and their role within their employing context. 
This paper will proceed as follows; the project management profession will be introduced and critically discussed before a summary of the literature on cosmopolitan and local identities is given. An initial synthesis will then be carried out exploring the relationship between identity theory and the theory of the professions. We then empirically examine the identity work of project managers in three firms through an analytical frame built around discourses of local and cosmopolitan orientation, from which conclusions are drawn on the implications of this for project managers and the profession itself.

\section{The Professionalisation of Project Management}

Project management is one of a number of contemporary 'expert occupations' (Reed, 1996) engaged in a process of professionalisation. Project management combines managerial and technical responsibilities, drawing on a proprietary body of knowledge and associated practitioner methodologies to plan, monitor and control projects in a range of sectors (Morris, 1997; Hodgson, 2002). The emergence of project management as a distinct role and occupation in the midTwentieth century owes much to technological advances in the 1940s/50s in engineering and construction (Morris, 1997), which led to the establishment of particular techniques in various 'megaprojects' in the US (Hughes, 1998). In the latter half of the last century, the field was dominated by engineering, in particular the defence industry and construction. In addition, more recently, project management has benefited from the emergence of Information Technology and New Public Management (Hood, 1991; McLaughlin et al, 2002; Dent et al, 2004) which attempts to improve public sector efficiency through the introduction of market-oriented reforms, including subcontracting, the compulsory tendering of work and greater reliance upon fixed-term, publicprivate partnerships projects (Hodgson, 2002). Project managers are typically employed within large organisations, where they help to realise the objectives of their employers, with a minority serving such organisations from independent and relatively small consultancies (Morris, 1997; Zwerman and Thomas, 2001).

Aspirations to professional status for the project manager evolved with the formation of professional associations in the USA, UK and elsewhere through the 1960s and 1970s (Morris et al, 2006; Hodgson, 2008). Despite these initiatives, until the turn of the $20^{\text {th }}$ century, project management continued to be regarded as a weakly institutionalised occupational field (Greenwood et al, 2002), in that there was little regulation of the production of producers in terms of occupational barriers to entry and no legal (or indeed other) institutionalised restrictions on the right to practice as a 'project manager'. 
In the early 2000s Zwerman and Thomas (2001; 2002) and Zwerman et al (2003; 2004), in a series of publications, summarised the discussions on the potential of project management to professionalise. This analysis, taken largely from the study of traditional professions such as law and accountancy and, what they termed 'semi-professions' such as nursing and social work, identified standard criteria defining professional status. These include; control over the occupational title; clear definition of the field; construction of and claim to a body of knowledge; and control of education, accreditation and licensure. Drawing conclusions on how project management might meet these criteria this work proposed, rather pessimistically, that there were considerable barriers to professionalising in line with the traditional model. The main challenge identified in this work was the central role of the corporation as the principal procurer of project management services and the inevitable dominance of the employer over influence wielded by any professional body. This work viewed corporations as vehicles to fragment professions like project management through activity such as company-specific training programmes and associated schemes to accredit professionals in line with company-specific standards. This fragmentation would therefore prevent the wider occupation forming into a cohesive whole. In addition, due to the international nature of project management, this work also proposed that governments as potential stakeholders are unable/unwilling to offer institutional arrangements to support professionalisation, thereby leaving little to counterbalance the dominance of corporations.

Nonetheless, since then project management has continued to gain attention and status, being more widely promoted as a vital capability in both managing knowledge-intensive work and in helping companies navigate uncertain business environments leading to its increasing adoption in new sectors and in business change interventions. This shift led to a more promising climate for the professionalisation of project management and significant opportunities for the professional associations that had previously emerged to represent the interests in this field (Hodgson and Muzio, 2011). In light of these developments, an alternative argument proposed that project management was entering a deliberate and rapid phase of professionalisation (Hodgson, 2002, 2008) - albeit one which was enabled and framed by the influence of corporations as employers. As larger numbers of project managers were required and many corporations were unable or unwilling to train their own, many turned to professional associations as a reliable source of knowledge and accreditation structures for competent and 'professional' project managers.

This narrative resonates strongly with the wider debates concerning the emergence of the new 'corporate professions' (Muzio et al, 2011; Paton et al, 2013; Hodgson et al, 2015). Here, it is argued that many expert occupations located within corporations, such as Human Resource Management, 
Supply Chain Management and Project Management, are nonetheless professionalising. To do so, however, such 'corporate professions' must handle the tensions created by the existence of the competing institutions of professional body and employing corporation.

The issue at the root of many of the debates around professionalisation is the occupation's claim to control practice through the definition of a 'Body of Knowledge' (BoK) and licensing practice on the basis of this. One distinguishing feature of project management, and to a great extent the source of the issue explored in this paper, is the effectiveness with which the various associations that represent it have managed to construct standard 'Bodies of Knowledge' (BoK) (Morris et al, 2000; 156), reflecting 'the ontology of the profession; the set of words, relationships and meanings that describe the philosophy of project management'.

The existence of project management BoKs and the associated artefacts such as standard templates and process documentation has created two dilemmas, which represent sources of conflict for the practicing project manager. The first is the difficulty in applying a standard project management body of knowledge to a pluralistic environment in a diversity of contexts (Morris, 2006; Cicmil, 2009) that represent all of the industry sectors and activities that employ project managers. The second is the fit between the use of the limited, formal and often process-based, knowledge (episteme) contained in the BoKs and the use of other types of knowledge such as skill (techne) and practical wisdom (phronesis) (Morris, 2013) which may be required for effective domain-specific application.

Caught between the horns of this 'double dilemma' project managers are torn between affiliation with the 'rock' of their profession or the 'hard place' of their employer. Despite these dilemmas, project management has emerged as a leading new corporate profession with growing professional associations supported by BoKs and associated artefacts such as career structures and knowledge sharing forums. This has brought project management both enhanced status and increasing credibility as a profession and now represents a valid role affording meaning and a level of security to those joining it. The double-dilemma, however, remains, and is dealt with on a daily basis by practicing project managers who would wish to claim professional status. The way in which such project managers negotiate these dilemmas is the focus of this paper.

\section{The Identity of the Project Manager}

Project management now plays a major role in defining work identity for many in modern organisations. More significantly, project management is increasingly seen as not merely something a person does, but something a person is - a recognisable work identity. To understand the nature 
and formation of this identity, we turn to recent research in the field of organisation behaviour which explores 'identity work', the effort required to create and maintain a recognisable work identity.

Alvesson and Willmott define work identities as reflexively organised and temporally informed narratives which are "productive of a degree of existential continuity and security" (2002, p. 626). Hence identity work is a process whereby "people are continuously engaged in forming, repairing, maintaining, strengthening or revising the constructions that are productive of a precarious sense of coherence and distinctiveness" (Alvesson and Willmott, 2002, p. 626). In the first instance, project managers are exposed to two distinct influences shaping their identity and conduct: that of the organisation and that of the profession. The construction of a professional identity may therefore offer a route for career progression and enhanced status and reward within an organisation, but equally importantly may offer a source of validation to the individual which is external to the employer or bureaucratic structure within which $s /$ he operates. So it may be argued that professionalisation offers a degree of independence and autonomy; hence project managers, like other professionals, "are unlikely to be corporate clones, and may best be regarded as reflexive appropriators of organisational discourses in pursuit of valued work objectives and preferred identities" (Brown and Lewis, 2011, p. 886). We should not, however, exaggerate this independence from organisational structures and systems - as many who study professions have observed, professionalisation itself enmeshes an individual within a more complex disciplinary technology (Larson, 1977; Fournier, 1999) under the appearance of agency and personal development. The consequence of professionalisation is (at least in principle) a tension of loyalties, played out in practice in the individual and collective identity work of project managers.

In addition, Sveningsson and Alvesson (2003) argue that the intensity and persistence of identity work varies between organisational contexts, differing between relatively stable contexts and those characterised by complexity, fragmentation and change. Project work marks an important position between these extremes; in project-based organisations, the project itself may represent a zone of relative stability, offering ontological security and clarity of purpose, meaning and role in what is otherwise a complex, fluid and precarious context. Such spaces are of vital significance for the construction of a project manager's identity, as "work identities are constituted within organisationally-based discursive regimes which offer positions, or epistemological spaces, for individuals and groups to occupy" (Clarke et al, 2009, p. 325). Therefore this leaves two sets of tensions for the project manager to reconcile when constructing a self-identity: that between the profession and the employing organisation and that between the organisational contexts offered by 
differing employers. These tensions can best be understood by first analysing the identity of the project manager in relation to a classic sociological framework, by exploring their cosmopolitan and/or local orientation (Gouldner, 1957, 1958).

\section{Cosmopolitans and Locals}

There is a long tradition of studying the local or cosmopolitan orientation of individuals in society, tracing back to Robert Merton's "Social Theory, Social Structure" (1968) although it is Merton's student Alvin Gouldner who is most typically cited on the theme of localism and cosmopolitanism. Gouldner develops this concept more fully in an organisational setting, differentiating cosmopolitan and local identities among college employees. Cosmopolitans, he suggests, are "low on loyalty to the employing organisation, high on commitment to specialised role skills, and likely to use an outer reference group orientation", while locals are the inverse, "high on loyalty to the employing organisation, low on commitment to specialised role skills, and likely to use an inner reference group orientation" (Gouldner, 1957, p. 290). Importantly, for Gouldner, a key implication of this research was the illumination of "the tensions between the modern organisation's needs for loyalty and expertise" (Gouldner, 1958, p. 466) and resulting organisational conflicts.

The cosmopolitan versus local distinction is one that has particular pedigree in studies of professionals and expert occupations. For example, Shepard (1956, p. 298) differentiates cosmopolitan and local R\&D scientists as follows; "the former are oriented toward success as members of their profession, and their interest in the company is limited to its adequacy as a provider of facilities for them to pursue their professional work. Since they are productive, they may be valuable to the company, but such value is an almost accidental by-product of their work. The locals are good company men, but their interest is likely to be less in their work than in their advancement in the company." In later work, authors such as Raelin (1986) draw heavily on the 'local-cosmopolitan' difference in prescribing methods to accommodate professionals in organisations, suggesting dual career ladders as important means of retaining professionals with cosmopolitan orientation, while professionals with local orientation are more likely to be motivated by the prospect of managerial progression within a firm.

Unlike the cosmopolitanism of, say, Ulrich Beck (2006) which focuses on globalisation and the promise of a supranational politics of belonging, our focus here is specifically on organisational cosmopolitanism. In organisational terms, cosmopolitanism and localism is not concerned so much with physical territorial issues (local community versus national/global concerns) or indeed national 
culture and globalisation, but rather, an orientation and affiliation which goes beyond the immediate organisational context - the firm, plant or office - and an organisational context which may itself be geographically diffuse. A more appropriate reference point would be Kanter's (1995) description of the 'industry cosmopolitan' who is 'supralocal'. There are two elements to this: "the ability of 'cosmopolitans' to 'transcend' place, and their possession of competence or portable skills" (Halsall, 2009 , p. 139). Kanter equates this positioning with choice and independence of thought, presenting this in celebratory terms; "Local nativists value loyalties over choices, preferring to preserve distinctions and protect their own group. Cosmopolitans characteristically try to break through barriers and overcome limits; nativists characteristically try to preserve and even erect new barriers, most often through political means" (Kanter, 1995, p. 23-24). Here then the cosmopolitan is heroic, broad-minded and externally networked, unshackled by trivial local politics and informed by a higher set of values and 'universalisable' knowledge.

Thus, returning to the notion of professional as cosmopolitan, the affiliation of the ideal-typical professional is expected to be primarily to their occupation and the association which represents their profession. Their current employer or organisational context is of relatively minor or transient importance by comparison. Halsall (2009), for example, identifies professionalism as the link between Gouldner's categories and his notion of 'corporate cosmopolitanism' as the professional network serves as a carrier for 'universal values' which may hold the cosmopolitan community together. Such universal values are enshrined in the professionals' knowledge base, proprietary language and shared assumptions. They also exist in the shared belief that practice should be informed by an abstract and thus transferable body of knowledge. Other authors, such as Raelin (1986; 1126), build instead on Gouldner's implied suspicion of the cosmopolitan, warning that "the cosmopolitan-type professional (...) is at great risk of engaging in deviant/adaptive behaviour (with) the most deleterious effects on workforce productivity", while prescribing techniques to accommodate such valuable but untrustworthy cosmopolitan professionals in organisational settings. Raelin's work stands as an exception, however; in general, a more celebratory discourse around cosmopolitanism has dominated management academic debates (Halsall, 2009), exemplified by Kanter's description of the "industry cosmopolitan" 'for whom a global network of industryspecific or professional contacts throughout the world supplants “local identity" (1995, p. 84).

We would argue that the professionalisation of project management positions many project managers between these two roles; the pragmatic localist, embedded in the employing organisation, drawing on local knowledge versus the cosmopolitan professional, free to operate within the wider professional community, whose practice is increasingly informed by an abstract and transcendent 
body of knowledge uniting practitioners across industries and countries. Project management typically represents both organisational position and professional identity - the former locates the project manager in an organisation, subject to the demands of an employer, while the latter locates the project manager within a broader occupational (and increasingly professional) community. The construction of a professional identity therefore offers a source of validation for the project manager which is not directly dependent upon the employer or the bureaucratic or contractual structure within which he/she operates. However, this relative ambivalence towards organisational pressures may be at the cost of "disciplinary practices that transform professionals in organisations into managed and self-managing subjects" (Brown and Lewis, 2011; 887).

In this paper, we explore the dynamics of these competing pressures and modes of identity regulation on the contemporary project manager. In particular we seek to assess the consequences of this identity work (Alvesson and Willmott, 2002) through which project managers negotiate between local and cosmopolitan discourses to maintain a valued identity.

\section{Methodology}

This research was undertaken as part of a larger study into the position of project management within the contemporary organisational landscape. This research was qualitative in nature using mixed methods to construct a case study of the project management occupation. This case study was built using two methods; semi-structured interviews and examination of company documentation. The defence industry was chosen because, with the construction industry, it boasts a history of project management use; as an industry, it is mature in its practice of project management and at the forefront of work to professionalise the occupation. Therefore this context provides a rich environment to research all aspects of professionalised project management.

The research involved fieldwork that took place within three of the largest defence/engineering companies operating globally which we have named 'RadarCo', 'DefenceCo' and 'MarineCo'. All three companies; are rated within the top 10 defence contractors in the world; hold major global contracts; have a major presence in the UK; carry out work in all areas of the project lifecycle; and utilise project management as one of their prime organising methodologies. RadarCo currently has 75,000 employees and is one of the world's largest companies designing and producing radars and other sensing equipment for use on a variety of defence platforms. DefenceCo currently has 100,000 employees and operates in all defence markets, land, sea and air, producing a variety of electro mechanical systems, products and platforms. MarineCo currently has 30,000 employees and 
operates primarily in the warship and submarine construction and maintenance business. As these are primarily UK-based organisations, the professional association referred to almost exclusively in the interviews and other documentation was the APM.

Thirty-nine project managers were interviewed, using a structured snowball sampling approach. In each organisation, we requested that our gatekeeper arrange interviews with a set of managers reflecting a broad range of ages, levels of experience and seniority and, as far as possible in a maledominated industry, including both male and female managers. The result was a cross-section of ages (from 24 to 63 years), levels of experience (from 1 to 35 years) and grades of seniority (from first role to project director). Table 1 contains details of those interviewed.

$\underline{\text { Table } 1 \text { - Characteristics of interviewed project managers }}$

\begin{tabular}{|l|c|c|c|c|c|}
\hline & $\mathbf{2 0 - 2 9}$ & $\mathbf{3 0 - 3 9}$ & $\mathbf{4 0 - 4 9}$ & $\mathbf{5 0 - 5 9}$ & $\mathbf{7 6 0}$ \\
\hline AGE & 1 & 10 & 17 & 9 & 2 \\
\hline
\end{tabular}

\begin{tabular}{|l|c|c|}
\hline & $M$ & $F$ \\
\hline SEX & 35 & 4 \\
\hline
\end{tabular}

\begin{tabular}{|l|c|c|c|}
\hline & PROFESSIONAL & DEGREE & OTHER (TRADE/MILITARY) \\
\hline HIGHEST QUALIFICATION & 15 & 19 & 20 \\
\hline
\end{tabular}

\begin{tabular}{|l|c|c|}
\hline & YES & NO \\
\hline PRIOR OCCUPATION (BEFORE PM) & 35 & 4 \\
\hline
\end{tabular}

\begin{tabular}{|l|c|c|}
\hline & YES & NO \\
\hline MEMBER OF PROFESSIONAL BODY & 14 & 25 \\
\hline
\end{tabular}

Notes:

1) Qualifications: Degree and Other - only highest qualification counted therefore numbers add to 39 no interviewees were without some sort of qualifications.

2) Professional memberships and qualifications - some project managers had professional qualifications but were not currently members of a professional body others were members but were not professionally qualified.

The interview schedule contained a number of questions structured around three sections; (A) perceptions and experiences of project management as a career, (B) reflections on the status of project management, both locally and more widely, and (C) beliefs about skills, competencies and effectiveness associated with the project manager role.

These methods were supplemented by participant observation carried out during a series of incompany visits by researchers over the period of the research project to gain immersion in the 
context. Company documentation (including management structures lifecycle guides, processes and procedures and role descriptions) were also examined to inform the interviews and create a richer picture of the background to the practice of the occupation within these organisations.

Appendix 1 details the relationship between the interview schedule, the coding framework and the emergent themes related to cosmopolitanism and localism used to inform the analysis in this paper. Semi-structured interviews were used to provide flexible and detailed accounts through the joint construction of meaning in a social encounter, following Holstein and Gubrium's (1995) concept of the 'active interview'. Interviews followed a standard protocol generated by researchers, lasted between 30 minutes and 2 hours and were digitally recorded, then transcribed and anonymised. Data analysis was an inductive, iterative process whereby axial and selective coding (Strauss and Corbin, 1998) was conducted in sequence by one researcher, before being validated by a second. Once agreed, categories were then examined for discursive coherence. For this paper, the analysis has focused upon codes associated with the local or cosmopolitan orientation of the project manager.

\section{The Project Manager as Professional}

While project management has for many years been in the public eye, mainly due to the exposure gained by large-scale construction and engineering projects, the emergence of other projects closer to the public's attention such as the Olympic Games have further served to raise its stock as a mainstream occupation. While the rhetoric of, and increasing membership figures published by, associations such as the APM and PMI would suggest a strong and coherent profession, this view was only partially reproduced in this research.

On one hand there was evidence of a strong discourse, espoused predominantly by the younger or newer project managers interviewed, which described increasing status of project management, typically associated with its growing professionalisation. Those who espoused this discourse tended to be very active in the profession, maintaining membership, attending developmental events and generally displaying an enthusiasm for its activities believing that the profession was itself a vehicle for career progression. The views of those who adhered to this position are neatly summarised in the following quote: 
If follow the APM closely, I'm a member of the APM etc. I'm keen to maintain that and continue that to establish a career path for people, a profession in its own right that has transferable skills no matter what sector you're in.'

AM, Project Director, MarineCo North.

The depth of this discourse was further illustrated by some linking the profile and standing of the profession in relation to other occupations with their own personal worth and ultimately career success. This project manager cites the achievement of a Royal Charter for the APM as a proxy which would increase the cache of the profession and therefore individual project managers improving their standing in relation to those of the other more established professions.

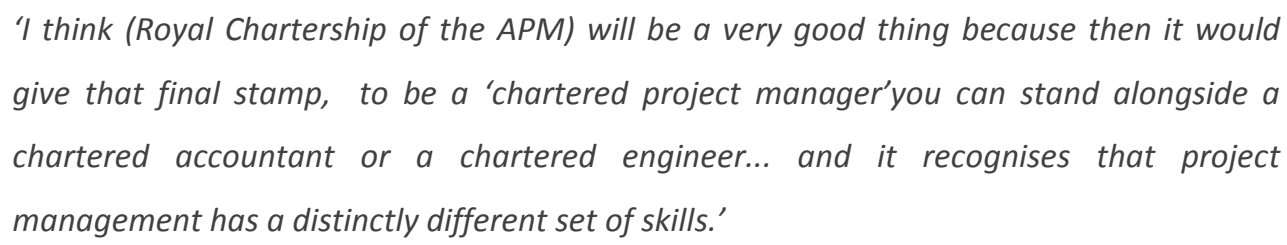

TC, Project Manager, DefenceCo.

This belief in recognising the importance of the occupation and increasing its standing with regard to other occupations was a recurring theme amongst the majority of project managers regardless of their view on the wider professional debate.

However on the other hand this professionalisation discourse indicating a cosmopolitan orientation was countered by the views of others who indicated a more local orientation. In this sample, three quarters of project managers interviewed were not members of any professional association, and several, especially older and longer-serving staff, appeared uncertain about the value of professionalism, or of affiliation with a professional body. One statement made by an experienced project manager in relation to the APM typified a widely-held view;

'I'm not sure what (the APM) are all about. What are they doing; what are they saying; what are they giving me that's going to make me better; what am I going to learn?'

PB, Programme Manager, RadarCo.

This 'localist' discourse tended to be characterised by project managers who had spent much, if not all, of their career within one company and who therefore value their familiarity with the company context often prioritising it over their occupational skills. This discourse was evident on two subthemes, the first characterised by pride in their mastery of the technical detail of the work of the company, in this case engineering. In the following quote this project manager indicates his 
preference for working with the team doing technical work, in effect abandoning the methodologies of the project management occupation in favour of displaying his technical expertise in the belief that this is the best way to progress the work.

\footnotetext{
'The way I run my projects, I'm hands on. You know (...) the way we work here, basically, we've got to chase the designers up to get our projects (delivered on time). And, my approach is I go with them down on site and I'll say " what's the problem?" and I try and work with them to get the design out quicker.'
}

JG, Project Manager, MarineCo West.

The second sub-theme is in prioritisation of local knowledge of people and places over occupational knowledge. Here this project manager indicates that in his view knowing who and where is the best way of getting the job done rather than using the power of the position that accompanies being the project manager.

'It's based on knowing the guys... on working with the guys for years. You build up relationships, some good, some bad, and that's how you get work done. So, it's getting to know who to go to and them giving you enough respect and doing it because they know you, that type of thing, rather than because your position causes you to do that.'

AC, Project Manager MarineCo North.

Interestingly those project managers who prioritised their association with the company over their association with the professional group also sought alignments with those in other occupations which were often their previous profession. A project manager who had worked as a design engineer claimed:

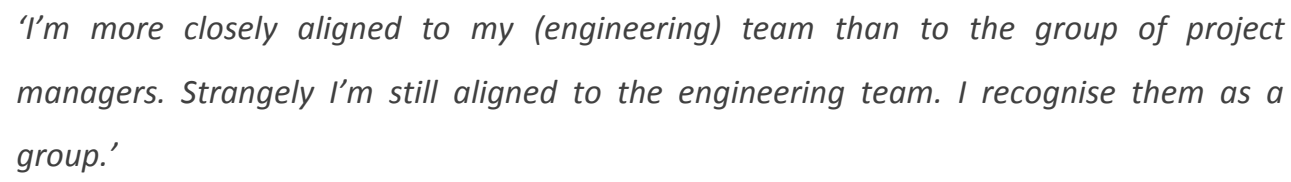

IW, Project Manager, MarineCo North.

While these project managers displayed a very acute form of 'localism' often rejecting the occupation of project management in favour of immersion in the activity of the company or affiliation with another professional community there was another group of project managers, who although predominantly 'localist', recognised the professional discourse in a rather limited way as an organisational profession: something that is internally constructed by the company rather than as a wider community of practice. The following statement was typical of this type of project manager; 
'We do have a project management council internally (to the company) but other than that I don't attach myself to anything else (external professional body).'

LA, Program Manager, RadarCo.

This association purely with the in-company project management community itself indicates a strong local orientation as this project manager sees the occupation as company-bounded with artefacts of the profession constructed by the company for those within the company.

However, rather ironically, despite this tendency towards localism, all three corporations involved in this research added a different, and somewhat contradictory, dimension which both reinforced the cosmopolitan discourse of professionalism while capturing it within the local company discourse by emphasising the importance of affiliation with the professional body as a route to wider career progression. This quirk is highlighted by a relatively junior project manager here:

'Well, it's been made quite clear, for career progression it's quite important to have (APM) membership/accreditation. I was told (by my company) from the start.'

MM, Project Engineer, MarineCo West.

Further investigation into career progression revealed that all three companies had, over the last few years, adopted a career structure that was reflective of the APM occupational structure and two companies had gone as far as having their career structure accredited by the APM: a practice that has now become more widely adopted across industry. This alliance between corporation and professional body is made possible as companies are also encouraged to become affiliated to the professional body in what is primarily a resource-sharing partnership - the resource being the career development and professional accreditation system.

Moving beyond the more general discourses around affiliation to profession or company, another differentiator between the cosmopolitan and local views emerged in relation to the discourses around professional knowledge and methodology and their transferability between contexts such as companies and industries.

Some project managers were adamant that their skills, knowledge and methodologies are universal. 
'Yes, absolutely transferable, it's all about the principles of project management and the soft skills we've talked about and you can apply those anywhere. I've moved from the automotive industry to the aerospace industry, to the defence industry, I'm using very similar skills all the way through.'

JS, Project Manager, MarineCo South.

Interestingly this is a view that seems to have gained a considerable degree of corporate support as one senior project manager operating at board level of his company noted in relation to the recruitment policy of his company;

'We've stopped just recruiting project managers from people with technical qualifications and we now recruit graduates into the project management graduate training scheme who show talent for project management. So, we've got some people in our scheme with some very strange backgrounds... one of our best project managers has a degree in reproductive biology. It's not natural for a ship builder - but actually she does extremely well.'

TC, Senior Project Manager, DefenceCo.

However despite this company position the cosmopolitan orientation was rejected by other project managers who prioritised their in-company knowledge over their project management skills and this view tended to be explicated in two ways. First, and linked to the previous findings, many project managers spoke of the importance of their domain knowledge in relation to product or technology;

'Because I'm working in a defence and engineering company you need that kind of link and you need to know the engineering side of stuff. So, having the engineering background really helps.'

MV, Project Manager, RadarCo.

Others made it clear that experience of the industry and of their immediate environment such as their in-company network of contacts was the important factor.

'Regardless of how experienced the project manager was, or how clever, or how much training he'd had, the domain knowledge of the company and the industry sector is important, there's just no going away from that.'

DS, Project Manager, RadarCo.

However one interviewee neatly highlighted the middle ground: 
'You can make too much of domain knowledge. You need to understand the domain you're in. It's all right for our graduates because they come into the domain and they pick up the domain knowledge as they go through. I don't think (project management knowledge) is totally transferable but I think it's more transferable than many people like to make out.'

TC, Senior Project Manager, DefenceCo.

This suggests that the competence can extend beyond a singular company or industry but does not define the larger boundary. However another interviewee supported the transferability of project management while indicating a limit to applicability.

If it was going onto a production environment in car manufacture, or if it was going into another manufacturing environment like that where you're making a product then I think very easily transferrable from here (the aircraft industry).

DM, Project Manager, RadarCo.

Here industry context (rather than industry sector or immediate company or product environment) was suggested as the boundary of transferability.

However some pushed this further and rejected any idea of a boundary, arguing that regardless of previous experience, project managers could become effective in any industry if they had the correct project management competence and:

...as long as that person coming in is also given some guidance and support about (domain based knowledge such as) the contract framework of the customer and the product knowledge.

PR, Project Manager, MarineCo South.

Another project manager extends this argument endorsing the transferability of project management skill but with the caveat that technical aspects of each industry are also important: 
'I think there are a number of skills which I have which are completely transferable (across industry sectors). In theory, a project manager can work in any industry (because) the basics of project management are the same. However, obviously, there are technical skills which are specific to each industry. So, for example, if I was to leave defence and aerospace for (a job in) construction it's highly likely I would either have to take a side step or a slight step down because in terms of knowledge and of that particular industry I wouldn't have the level.'

HA, Project Manager, RadarCo.

Here this project manager indicates that the way to move beyond boundaries by obtaining the required domain knowledge is to take a reduction in grade, essentially moving 'closer to the coalface' so providing the opportunity to learn the industry from the bottom-up. This discourse was common and suggests that the key factor is competence in the use of the methodologies of project management as all other aspects of 'the job', the domain knowledge such as client and commercial environment, product technology and internal network, could be learned through time given the opportunity and assuming a capable and receptive individual.

However this project manager then went on to suggest that a move to an entirely different industry, such as the Information Technology industry, may not be practical as the learning curve in industry context and product technology may be too great.

Overall, it should be underlined that respondents who articulated exclusively cosmopolitan or exclusively localist views were in the minority. Among the 37 project managers interviewed here, only 5 expressed views that were purely cosmopolitan, and only 6 expressed views that were purely local.. The majority, constituting 25 project managers, expressed views that were a mix of cosmopolitan and local orientations, with 1 interviewee expressing no view that related to either orientation. This reflects the competing pressures upon project managers, and the difficulty in maintaining a purist position. Our focus now turns to understanding the contrasting discourses evident in these accounts, before examining how those 'in the middle' sought to reconcile pressures towards localism and cosmopolitanism so as to present a coherent work identity as a project manager.

\section{Making Sense of Conflicting Discourses}

This research therefore reveals three distinct tensions reflected in the discourses of the project managers interviewed. These tensions, we argue, reflect the dilemmas created by difficulty in 
applying a standard body of knowledge to a pluralistic environment and finding a fit between the use of the knowledge contained in the BoKs and forms of knowledge. These tensions are summarised in Table 2.

Table 2 - Summary of Tensions

\begin{tabular}{|c|c|c|}
\hline Tension & \multicolumn{2}{|l|}{ Explanation } \\
\hline \multirow[t]{2}{*}{1 - Primary affiliation } & \multicolumn{2}{|c|}{ Commitment to profession vs commitment to employing corporation } \\
\hline & PM identifies with profession & PM identifies with corporation \\
\hline \multirow[t]{2}{*}{2 - Knowledge and skill } & \multicolumn{2}{|c|}{ 'Values professional knowledge' vs 'values domain knowledge' } \\
\hline & $\begin{array}{l}\text { PM practises using professional BoK } \\
\text { and associated system }\end{array}$ & $\begin{array}{l}\text { PM practices using domain knowledge } \\
\text { and in-company system }\end{array}$ \\
\hline \multirow[t]{2}{*}{3 - Model of practice } & \multicolumn{2}{|c|}{ 'Practices at a strategic level' vs 'practices at the detail level' } \\
\hline & $\begin{array}{l}\text { PM operates at a high level where } \\
\text { professional BoK and system can } \\
\text { work }\end{array}$ & $\begin{array}{l}\text { PM operates at detail level where } \\
\text { domain knowledge is most useful }\end{array}$ \\
\hline
\end{tabular}

In the first tension, project managers are torn between affiliation to the profession and affiliation to their employer, with two opposing discourses characterising this tension. In one discourse, project managers identify more strongly with the profession, feeling supported by the associated artefacts such as an increasingly robust and visible professional body and extensive network of occupational colleagues. For them project management is very much a coherent profession, with a universallyapplicable methodology and extensive support group of fellow practitioners. In addition, it is viewed as independent of any specific employment context - consequently the project manager, master of the body of knowledge and skilled in the craft, is at liberty to travel between companies and across industries carrying sought-after, transferable expertise. These project managers are comfortable with the 'supralocal' profession, seeing the corporation as a stepping stone on a larger career journey rather than a destination in itself. By contrast, in the opposing discourse, project managers identify more strongly with the employing corporation. They in turn draw safety and comfort from the artefacts of their immediate context identifying more strongly with the business of the corporation and their work colleagues regardless of occupation. Here project management is often not regarded as a 'proper' profession; instead, the role is seen as purely an extension of the incompany process and therefore of limited external validity. Consequently, in this position, the project manager is tied to the immediate employment context, largely oblivious to the wider professional network and associated opportunities. These project managers prefer the tangibility of 
the immediate employing institution, frequently conflating the level of regard in which they are held by their employing company with career success.

The second tension sees project managers differ in how they value the professional skills they possess. In one discourse being skilled in the competencies of project management, as outlined in the professional 'Body of Knowledge', is of prime importance. This discourse is underpinned by the belief that these competencies are universal and will help to deal with any role related situation that should confront them. Project managers who demonstrate this view therefore tend to value formal qualifications such as professional accreditation against the 'Body of Knowledge' or university certification over local knowledge gained through experience. However, in the opposing discourse, others see domain knowledge of the company's product and process as much more important. This discourse is underpinned by a belief that there are severe limitations in project management 'Body of Knowledge' and to be effective they need to understand in more detail the local and technical aspects of the job being managed, rendering less relevant any formal project management credentials. Those with this view see project management as unique to the operation of the company and must be learned through immersion in that context.

Finally, the third tension is characterised by two opposing discourses describing how the mode of practice of the project manager; in other words, how the individual project manager enacts their role. In one discourse some project managers explained how they try to work at a strategic level, managing by application of professional methodology and expertise in a more abstract and formal way. These project managers described how they performed their role strictly within the boundary of the occupation. Here, technical details and local politics often present themselves as a 'trap', dragging the project manager 'into the weeds', in the words of one respondent. However, in the opposing discourse project managers described how the importance of grasping such local detail and described how they would manage more tactically, through detailed involvement in the process of work, engaging more closely and informally with other employees. For them maintaining the integrity of the project management professional role was secondary to completing the work and these project managers frequently engaged in tasks outwith (and often subordinate to) their role to 'get the job done'. 


\section{Understanding Orientations}

Two dialectically-opposed professional orientations can be identified here, characterised by the differing ways in which project managers negotiate tensions regarding their primary affiliation, knowledge domain and mode of practice. Table 3 summarises these orientations.

Table 3-Cosmopolitan and Local Orientations

\begin{tabular}{|l|l|}
\hline Cosmopolitan Orientation & Local Orientation \\
\hline profile in the market & $\begin{array}{l}\text { Low commitment to professional group due to } \\
\text { priority placed on company }\end{array}$ \\
\hline $\begin{array}{l}\text { High emphasis placed on role skills due to the } \\
\text { value they add to transferability }\end{array}$ & $\begin{array}{l}\text { Low emphasis placed on role skills due to value } \\
\text { placed on in-company/industry domain knowledge. }\end{array}$ \\
\hline $\begin{array}{l}\text { High value placed on external training academic } \\
\text { qualifications due to their value as an aid to career } \\
\text { mobility }\end{array}$ & $\begin{array}{l}\text { Low value placed on external training due to } \\
\text { emphasis on in-company process/product training } \\
\text { and experience as valued by the company }\end{array}$ \\
\hline $\begin{array}{l}\text { High tendency towards a strategic orientation in } \\
\text { mode of practice due to emphasis on career } \\
\text { progressions }\end{array}$ & $\begin{array}{l}\text { Low tendency towards a strategic orientation in } \\
\text { mode of practice due to tendency to become } \\
\text { immersed in the detail of the task. }\end{array}$ \\
\hline
\end{tabular}

The cosmopolitan orientation depicts project management as a completely transferable professional system of knowledge and practice, based on a universal and portable body of knowledge, detached from contextual contingencies such as product, industry or employing organisation. Adherence to the professionally-set role boundary is strictly enforced. This cosmopolitan orientation sees domain knowledge of industry, and technical expertise of product as easily acquired and of marginal importance. Project managers practice at a strategic level using project management as a defence against the need to become involved in the detail of the work. In career terms, such project managers are free agents; the currency which facilitates transfer between jobs and across industries is their professional competence. Primary affiliation is to the profession and all of the artefacts it contains. Project managers with this orientation tend to value freedom over safety. This orientation to a great extent has been supported by the growth of the profession in recent years both in terms of increasing numbers of project managers who belong to a professional body and also in the increasing availability of formal qualifications provided by professional bodies and higher education providers. 
The local orientation sees project management is fundamentally an extension of an in-company technical role, which prioritises extensive knowledge of the product and technology, and domain knowledge of the organisation and industry. Here, project managers work as required by the corporation while taking little notice of professional boundaries. This tends to meant that project managers revel in the detail effectively demoting themselves by carrying out tasks below their organisational level. Project management is seen to provide, at best, some simple and relatively limited tools and techniques which must be evaluated for relevance and in all likelihood adapted to local organisational context. Due to this reliance on local knowledge the transferability of project management competence is seen as limited. Here project managers are captive; their value only appreciated within the domain of the employing company. Primary loyalty is to the employing company with the imperative being to preserve and enhance that employment status. This orientation is supported by the nature of the employment market for the project management professional, which (in line with other new corporate professions) tends to be dominated by large corporations who provide a strong point of reference and promote the importance of loyalty and affiliation.

For many, however, such purist positions were not tenable given the demands of their everyday activities. In addition to the simple identification of opposing cosmopolitan and local orientations, the empirical analysis revealed a third, more prevalent and more complex, intermediate orientation where project managers attempt to either negotiate the tensions between the basic cosmopolitan and local orientations or to integrate them in distinctive ways. This intermediate position draws upon a blend of discourses in an attempt to make sense of and even reconcile the tensions identified above.

Several interviewees in this position draw attention to areas in which the interests of profession and employing corporation coincide to support their position. A prime example here would be instances of apparent collusion between company and profession. As noted above, traditionally professions and employers have been viewed in opposition, with professions, to an extent, providing an occupational shelter protecting practitioners from exploitation by employers. However a feature of the new corporate professions in general and of project management in particular is greater cooperation with corporations (Paton et al, 2013). The company membership system operated by the APM, of which each research company is part, is the most visible manifestation of this increased cooperation. While corporate membership in itself may be of little more than symbolic significance to the individual project manager, in some cases this acts as a catalyst for the implementation of mechanisms of greater consequence: the most direct of these being the adoption by the corporation 
of the qualification system and career path developed by the professional body. Other less direct consequences also result where corporations borrow, albeit informally, from the practices of the professional body. This is exemplified here by the implementation within RadarCo of a 'pseudo' professional forum named the Project Management Council which 'mimics' the knowledge sharing forums of the APM. These practices, supported by the employer, in effect 'force' project managers, regardless of individual orientation, to engage with the wider professionalisation discourse. For those of a cosmopolitan orientation this is welcomed but for those of a local orientation this is discomforting, bringing not only an awareness of the wider profession but more crucially encouraging adoption of profession-wide competences that they often reject. These mechanisms serve to confront local project managers with an external occupational reality which impinges upon and questions their mode of practice within the company. They in effect encourage a different positioning, whereby practitioners see the potential to affiliate with both corporation and profession at the same time.

A second area in which intermediate positions are articulated relates to the transferability of project management methodology and skills the discourse. While the cosmopolitan orientation assumes the universal transferability of the methodology and competence of project management and the minor relevance of domain knowledge, the localist orientation prioritises domain knowledge while marginalising the universal utility of project management methodology and competence. To reconcile these positions, several project managers interviewed articulate more sophisticated discursive positions which highlight possible versions of middle ground. The first of these uses as its point of departure the discourse of the local orientation. Here, belief in the primacy of local domain knowledge is retained but attenuated as some value is accorded with broader project management methodology and competence. This reconciliation is facilitated by arguing that local knowledge is valuable, but not bounded by company but perhaps extending to market sector or even to the industry more widely. How far this flexible boundary extends differs between respondent, but for these project managers it is clear that project management methodology and competence is 'slightly' transferable, in certain conditions; a moderated localism moving closer to the cosmopolitan discourse. A second position adopted here takes as its point of departure the discourse of the cosmopolitan identity. While belief in the universal applicability of project management methodology and competence is retained, this is attenuated by an increased value placed on domain knowledge. Here the project manager discharges the role as guided by professional practice but recognises that some customisation is required to the employment context. Such respondents accept that effective practice is reliant upon the possession of some, limited level of domain 
knowledge. Here, it is typically argued that transferability is possible but requires some kind of reorientation program, to supplement universal professional project management knowledge with a level of domain knowledge. Again, the extent of local reorientation necessary varies between respondent, but overall reflects a moderated cosmopolitanism making concessions to the localist position.

The picture of competing discourses surrounding the cosmopolitan and local orientations of project managers is captured in Table 4 below.

\section{Table 4-Summary of Orientations}

\begin{tabular}{|c|c|c|}
\hline Cosmopolitan Orientation & Intermediate Orientations & Local Orientation \\
\hline $\begin{array}{l}\text { High commitment to } \\
\text { professional group due to its } \\
\text { profile in the market }\end{array}$ & $\begin{array}{l}\text { Corporation and profession } \\
\text { are collaborating leading to } \\
\text { strong professional affiliation } \\
\text { linked with full commitment } \\
\text { to an employing organisation. }\end{array}$ & $\begin{array}{l}\text { Low commitment to } \\
\text { professional group due to } \\
\text { priority placed on company }\end{array}$ \\
\hline $\begin{array}{l}\text { High emphasis placed on role } \\
\text { skills due to the value they add } \\
\text { to transferability }\end{array}$ & $\begin{array}{l}\text { 'Intermediate-local' where } \\
\text { occupational knowledge and } \\
\text { skill is transferrable but only } \\
\text { within a bounded context }\end{array}$ & $\begin{array}{l}\text { Low emphasis placed on role } \\
\text { skills due to value placed on } \\
\text { in-company/industry domain } \\
\text { knowledge. }\end{array}$ \\
\hline $\begin{array}{l}\text { High value placed on external } \\
\text { training academic qualifications } \\
\text { due to their value as an aid to } \\
\text { career mobility }\end{array}$ & $\begin{array}{l}\text { 'Intermediate-cosmopolitan' } \\
\text { where transferability of } \\
\text { occupational knowledge and } \\
\text { skill is achievable only }\end{array}$ & $\begin{array}{l}\text { Low value placed on external } \\
\text { training due to emphasis on } \\
\text { in-company process/product } \\
\text { training and experience as } \\
\text { valued by the company }\end{array}$ \\
\hline $\begin{array}{l}\text { High tendency towards a } \\
\text { strategic orientation in mode of } \\
\text { practice due to emphasis on } \\
\text { career progressions }\end{array}$ & $\begin{array}{l}\text { through an extensive process } \\
\text { of reorientation. }\end{array}$ & $\begin{array}{l}\text { Low tendency towards a } \\
\text { strategic orientation in mode } \\
\text { of practice due to tendency to } \\
\text { become immersed in the } \\
\text { detail of the task. }\end{array}$ \\
\hline
\end{tabular}

In summary this indicates two additional orientations. First the 'intermediate-local' where knowledge is transferrable to adjacent industries but only within a bounded context so, for example, a project manager experienced in the automotive industry may become effective in the aerospace industry but may be unable to perform in the pharmaceutical or construction industries. And second 
the 'intermediate cosmopolitan' where transferability is universal across industries but only achievable through an extensive process of reorientation and familiarisation sometimes involving a period of immersion in the detail of the context.

It is therefore clear that the competing tensions created when the new corporate profession meets the employing corporation leave individual practitioners with significant identity work to engage in to make sense of their occupational role.

It would of course be too simplistic to ascribe these opposing positions neatly to the respective agendas of professional associations and employers, which are in practice very close (Paton et al, 2013). The profession, as represented by the professional bodies, quite clearly promotes the agenda of cosmopolitanism expounding the portability and applicability of project management. Corporations overtly collude by engaging with the professional body, through corporate membership, and adoption of its mechanisms and so, by association, support the same cosmopolitan agenda. However, in contrast, by providing long-term employment, promoting company loyalty and integrating project management methodologies into wider company processes, corporations (albeit somewhat covertly) support the local agenda. This complex and interwoven activity by both profession and corporation forces project managers to appropriate the norms and practices of the company which for some may be at odds with the specification of their role as a project manager as outlined by the profession.

\section{Conclusion}

The case of the professionalisation of project management has resulted in a complex and, arguably, contradictory state with project management professional caught in the horns of the double dilemma. Tensions arise from the challenge of applying a standardised body of knowledge to a pluralistic environment (Morris, 2006, 2013, 2014; Cicmil, 2009), and also the difficulty finding a fit between the formalised, prescriptive knowledge contained in the BoKs and the other, more grounded and contextual forms of knowledge required, such as skill (techne) and wisdom (phronesis).

This case builds on Gouldner's cosmopolitan and local typologies to articulate different responses on the part of project managers. In our interviews, we identify the ways in which project managers navigate this double dilemma, drawing attention to how that they orientate themselves in relation to their craft and the two main institutions of professional body and corporation that dominate their employment. We break down this rather binary distinction, identifying three tensions which 
individual project managers must reconcile to construct a valid identity. Some project managers draw heavily on the cosmopolitan discourse and others draw on the local; the majority, though, find ways to integrate both sets of discourses. This study therefore supports the proposition of identity as struggle (Sveningsson and Alvesson, 2003), as project managers work to reconcile the tension between cosmopolitan and localist discourses in search of a coherent position and professional identity.

The first, and possibly most important, contribution of this research is that in constructing the intermediate orientations, project managers are implicitly challenging the utility of the concept of portable bodies of knowledge and universal methodologies. As a result, many project managers prioritise their local knowledge including 'technical expertise' of the product or service combined with domain knowledge of company and industry over their mastery of the professional body of knowledge. This finding lends support to questions raised by Morris $(2006,2013)$ over the utility of formalised bodies of knowledge in their current form, and the considerable efforts put into their maintenance and promotion. In addition, on a wider canvas, this questions the wisdom of the strategy of professionalism for this occupational group.

Second, this research illuminates the persistent relevance of examining "tensions between the modern organisation's needs for loyalty and expertise" (Gouldner, 1958, p. 466). Within this professional group, these needs are at first glance mutually exclusive. The corporation clearly needs the expertise of the profession but in appropriating this expertise it exposes itself to the 'deviant' behaviours of cosmopolitans highlighted by Raelin (1986) where loyalty suffers at the hands of the larger opportunities afforded by universal employability. For some, reflecting Sennett's (1998) prognostication, such loyalty may be an anachronism. Here, instead, the promise of supralocal cosmopolitanism inherent in professional status offers an escape from the localist position of the 'lifer', tied to and dependent upon a single employer due to their reliance on local knowledge and status. Professionalism puts this tension to the test, as is evidenced by the variety of responses in our study.

Third, this research implies that both professional bodies and employers need to understand how to navigate these discourses to meet their own agendas. This reveals dual challenges. For the profession, the challenge is to convince locals to become cosmopolitans by adopting the trappings of professionalism but without relinquishing the loyalty that corporations' value. The challenge for the corporation is therefore the opposite, to capture the expertise of the cosmopolitan while gaining the loyalty they value. Ironically both institutions are complicit, often working together to meet different 
ends. We argue that attention to these issues may cast a valuable light on the compromises that professionalisation brings to this particular form of expert labour (Morris, 2013)

As this research was carried out within the UK and within the defence/engineering sector, care must be taken in extrapolating more widely. We would argue that similar tensions would play out more widely, particularly in contexts where project management professionalisation is relatively advanced and where corporations are engaged in building organisational capabilities in project management. However, we would call for research to explore the specific dynamics in other sectors and particularly internationally where the dynamics of professionalism and professionalisation vary significantly.

Finally, and more broadly, this research suggests that project management and the new corporate professions are rich in identity work and identity theory. In particular, we note the value of cosmopolitanism and localism as a lens through which to better analyse the ongoing evolution of the project management profession. We trust that academic work in this regard may go some way to remedying the 'hole in the head' which Peter Morris (2014) memorably diagnosed in the project management profession.

\section{References}

Alvesson, M. and Willmott, H., 2002. Identity Regulation as Organizational Control: Producing the appropriate individual, Journal of Management Studies, 39(5), 619-644.

Beck, U., 2006. Cosmopolitan Vision, Cambridge, Polity.

Brown, A.D. and Lewis, M.A., 2011. Identities, Discipline and Routines, Organization Studies, 32(7), 871-895.

Burrage, M. and Torstendahl, R., (eds.) 1990. The Professions in Theory and History, London, Routledge.

Clarke, C.A., Brown, A.D. and Hope-Hailey, V., 2009. Working Identities? Antagonistic discursive resources and managerial Identity, Human Relations, 63(3), 323-352.

Cicmil, S., Hodgson, D., Lindgren, M. and Packendorff, J., 2009. Project Management behind the façade, Ephemera, 9(2), 78-92. 
Crawford, L., Morris, P., Thomas, J., and Winter, M., 2006. Practitioner development: From trained technicians to reflective practitioners, International Journal of Project Management, 24(8), 722-733.

Dent, M., Chandler, J. and Barry, J., 2004. Questioning the New Public Management, Aldershot, Ashgate.

Fournier, V., 1999. The Appeal to 'Professionalism' as a Disciplinary Mechanism, Sociological Review, 47(2), 280-307.

Gouldner, A.W., 1957. Cosmopolitans and Locals: Toward an Analysis of Latent Social Roles - I, Administrative Science Quarterly, 2(3), 281-306.

Gouldner, A.W., 1958. Cosmopolitans and Locals: Toward an Analysis of Latent Social Roles - II, Administrative Science Quarterly, 2(4), 444-480.

Greenwood, R., Suddaby, R. and Hinings, C.R., 2002. Theorizing change: the role of professional associations in the transformation of institutionalized fields, Academy of Management Journal, 45(1), 58-80.

Halsall, R., 2009. The Discourse of Corporate Cosmopolitanism, British Journal of Management, 20, $136-148$.

Hodgson, D.E., 2002. Disciplining the Professional: The case of project management, Journal of Management Studies, 39(6), 803-821.

Hodgson, D.E., 2008. The New Professionals: Professionalization and the Struggle for Occupational Control in the Field of Project Management, in Muzio, D., S. Ackroyd and J.F. Chanlat (eds) New Directions in the Study of Expert Labour, London, Palgrave.

Hodgson, D.E. and Muzio, D., 2011. Prospects for Professionalism in Project Management, in Morris, P.W.G., Pinto, J. and Söderlund, J. The Oxford Handbook on Project Management, Oxford, Oxford University Press.

Hodgson, D., Paton, S. and Muzio, D., In Press. Something Old, Something New?: Competing Logics and the Hybrid Nature of New Corporate Professions, British Journal of Management.

Holstein, J.A. and Gubrium, J.F., 1995. The Active Interview, Thousand Oaks, CA, Sage. 
Hood, C., 1991. A public management for all seasons, Public Administration, 69(1), 3-19.

Hughes, T.P., 1998. Rescuing Prometheus: Four Monumental Projects That Changed the Modern World, New York, Pantheon.

Johnson, T.J., 1972. Professions and Power, London, Macmillan.

Kanter, R.M., 1995. World Class: Thriving Locally in the Global Economy, New York, Simon and Schuster.

Larson, M.S., 1977. The Rise of Professionalism: A sociological analysis. Berkeley, University of California Press.

McLaughlin, K., Osborne, S. and Ferlie, E., 2002. New Public Management: Current Trends and Future Prospects, London, Routledge.

Merton, R., 1968. Social Theory, Social Structure, New York, Free Press.

Morris, P.W.G., 1997. The Management of Projects, London, Thomas Telford.

Morris, P.W.G., Patel, M.B., and Wearne, S.H., 2000. Research into Revising the APM Project Management Body of Knowledge, International Journal of Project Management, 18(3), 155164.

Morris, P.W.G., Crawford, L., Hodgson, D., Shepherd, M. M. and Thomas, J., 2006. Exploring the role of formal bodies of knowledge in defining a profession - the case of project management. International Journal of Project Management, 24(8), 710-721.

Morris, P.W.G., 2013. Reconstructing Project Management reprised: A knowledge perspective. Project Management Journal, 44(5), 6-23.

Morris, P. W. G., 2014. Project management: a profession with a hole in its head or, why a change in the culture of academic support is needed for the profession. Engineering Project Organization Journal, 4(2-3), 147-151. 
Muzio, D., Hodgson, D., Faulconbridge, J., Beaverstock J. and Hall, S., 2011. Towards Corporate Professionalization: The case of project management, management consultancy and executive search, Current Sociology, 59, 443-464.

Muzio, D., Ackroyd, S. and Chanlat, J.S., (eds) 2007. Redirections in the Study of Expert Labour Basingstoke, Palgrave.

Paton, S., Hodgson, D. and Muzio, D., 2013. The Price of Corporate Professionalism: Analysing the Corporate Capture of Professions in the UK, New Technology, Work and Employment, 28(3), 227-240.

Raelin, J.A., 1986. An Analysis of Professional Deviance within Organizations, Human Relations 39(12), 1103-1129.

Reed, M.I., 1996. Expert power and control in late modernity: an empirical review and theoretical synthesis, Organisation Studies, 17(4), 573-597.

Shepard, H.A., 1956. Nine Dilemmas in Industrial Research, Administrative Science Quarterly, 1(3), 295-309.

Strauss, A.L. and Corbin, J.M., 1998. Basics of Qualitative Research: Grounded theory procedures and techniques, CA, Sage.

Sveningsson, S. and Alvesson, M., 2003. Managing managerial identities, Human Relations, 56(10), $1163-1193$.

Zwerman, B.L. and Thomas, J.L., 2001. Barriers on the Road to Professionalisation, PM Network, 15, $50-62$.

Zwerman, B.L. and Thomas. J.L., 2002. Exploring the potential for professionalization of project management. Proceedings of the Project Management Institute Annual Seminars and Symposium, San Antonio, Texas.

Zwerman, B.L., Thomas. J.L. and Haydt, S., 2003. Moving Project Management from Occupation to Profession. PMI Global Congress, Baltimore, Maryland, USA. 
Zwerman, B. L., Thomas. J.L. and Haydt, S., 2004. Professionalisation of Project Management: Exploring the Past to Map the Future, Project Management Institute. 


\section{Interview Schedule}

\section{Theme A: Career and Profession}

What made you move into PM from your previous role? (Push or pull?) Do you see PM as having brighter prospects for promotion?

What official training have you had in PM?.

What do you see yourself as - an engineer first and a PM second or a career PM?

Do you feel you have lost professional esteem by taking on a PM role? Do you see PM as a complimentary and accessible route into management for engineers?

Do you see PM as a profession in the same way as engineering - if not why not?

Do you feel part of a professional community?

Theme B: Status

Is PM given the same respect as other comparable positions like ops manager, or chief engineer?

Are you given the authority to do your job or is the power still held by the functions?

Are you able to manage at the level that you should?

What is the basis of your power/influence in the organisation as a PM? What can/could be done to enhance the status/influence of PM in your organisation?

Would a higher status for PM be a good thing for the organisation? Any downsides?

What do you think is the future for PM as a profession?

Who is responsible for professionalising PM?

\section{Theme C: Effectiveness}

What does your company understand PM to be?

What does good look like in PM?

What do you think makes an effective project manager?

What skills are important and have you been trained in these skills?

What kinds of knowledge contribute to your ability to do your work?

What or who influences your learning process?

How much do the knowledge and skills you have make you

in/dependent of industry/company?

In your work how much certainty or ambiguity is there in the PM

process?

Is there too much emphasis on imposed process?

Do you need to have domain knowledge to be effective or can a

generic PM fit into any context?

Do you think a prior professional background helps or hinders a PM?

\section{Appendix 1 - Coding Framework}

\section{Coding Framework}

Paper

PM PM as bureaucracy

Iron triangle

PM as community

PM as reflective practice

PM past and present

Generational divide

Engineering same as PM

Devolve PM to engineers

PM transferable

PM as control

CAREER PM always

Their route into PM

Autodidact

PM accidental

PM best for career

PM driven by employer

PROFESSION Profession-seen as

Profession - royal charter

Profession - APM corporate

Profession - APM individual

Credentialism

STATUS PM as ownership

PM as common sense

PM as broad scope

PM has respect

PM holding power

PM accountable

PM dragged into detail

PM community

Hierarchy

Engineering different to PM

PM not transferable

Engineer always

Engineering best for career

Profession - not seen as

ras

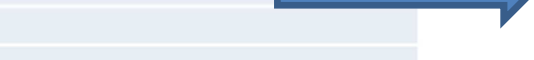

PM as limited

PM has not respect

PM not holding powe

PM not accountable

Unclear hierarchy for PM

EFFECTIVENESS Knowledge - experience

Knowledge - soft skills

Knowledge - technical skills

Knowledge - training

Domain knowledge needed

Value of structured

Domain knowledge not needed

methodology

alue to structured

PM through personal networks

PM as diplomat

\section{Cosmopolitan Discourse}

A Profession - seen as

$\mathrm{B}$ : $\mathrm{K}$ - domain tech $\mathrm{k}$ not needed

C: PM - transferable

D: PM community

$\mathrm{E}: \mathrm{K}$ - training

\section{Localist Discourse}

F: Profession - not seen as

$\mathrm{G}$ : K - domain tech $\mathrm{k}$ needed

$\mathrm{H}$ : PM - transferable not

I: PM through personal networks

$\mathrm{J}$ : K - technical skills

K: PM dragged into detail 